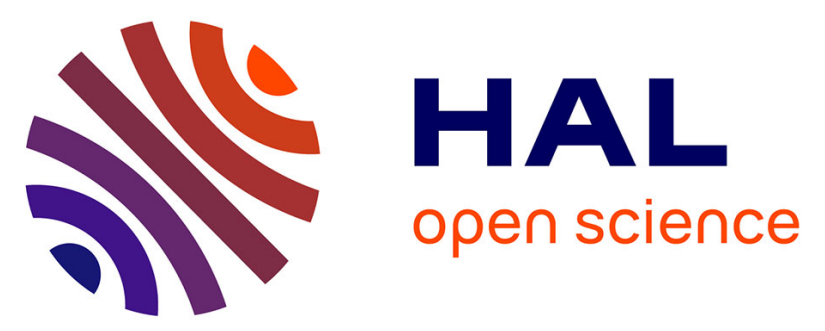

\title{
Improvement of AIN Film Quality Using Plasma Enhanced Atomic Layer Deposition with Substrate Biasing
}

Maxime Legallais, Hussein Mehdi, Sylvain David, Franck Bassani, Sébastien Labau, Bernard Pelissier, Thierry Baron, Eugénie Martinez, Gérard Ghibaudo, Bassem Salem

\section{To cite this version:}

Maxime Legallais, Hussein Mehdi, Sylvain David, Franck Bassani, Sébastien Labau, et al.. Improvement of AlN Film Quality Using Plasma Enhanced Atomic Layer Deposition with Substrate Biasing. ACS Applied Materials \& Interfaces, 2020, 12 (35), pp.39870-39880. 10.1021/acsami.0c10515 . hal03030507

\section{HAL Id: hal-03030507 https://hal.univ-grenoble-alpes.fr/hal-03030507}

Submitted on 30 Nov 2020

HAL is a multi-disciplinary open access archive for the deposit and dissemination of scientific research documents, whether they are published or not. The documents may come from teaching and research institutions in France or abroad, or from public or private research centers.
L'archive ouverte pluridisciplinaire HAL, est destinée au dépôt et à la diffusion de documents scientifiques de niveau recherche, publiés ou non, émanant des établissements d'enseignement et de recherche français ou étrangers, des laboratoires publics ou privés. 


\section{Improvement of AIN Film Quality Using Plasma Enhanced Atomic Layer Deposition with Substrate Biasing}

Maxime Legallais,* Hussein Mehdi, Sylvain David, Franck Bassani, Sébastien Labau, Bernard Pelissier, Thierry Baron, Eugenie Martinez, Gérard Ghibaudo, and Bassem Salem*

Cite This: ACS Appl. Mater. Interfaces 2020, 12, 39870-39880

Read Online

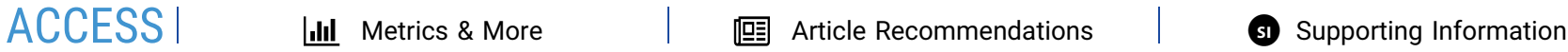

ABSTRACT: In recent years, plasma enhanced atomic layer deposition (PEALD) has emerged as a key method for the growth of conformal and homogeneous aluminum nitride (AlN) films at the nanoscale. In this work, the utilized PEALD reactor was equipped not only with a traditional remote Inductively Coupled Plasma source but also with an innovative additional power supply connected to the substrate holder. Thus, we investigate here the substrate biasing effect on AlN film quality deposited on (100) silicon. We report that by adjusting the ion energy via substrate biasing, the AlN film quality can be significantly improved. Indeed, compared to films commonly deposited without bias, AlN deposited with a platen power of $5 \mathrm{~W}$ displays a $14 \%$ increase in

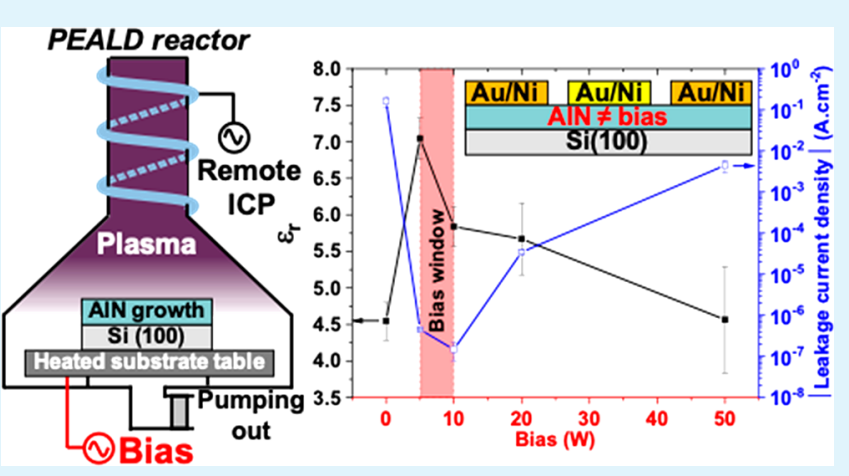
the number of $\mathrm{N}-\mathrm{Al}$ bonds according to $\mathrm{X}$-ray spectroscopy analysis. Moreover, after having integrated them into Metal-AlN-Si capacitors, the $5 \mathrm{~W}$ AlN film exhibits a permittivity increase from 4.5 to 7.0 along with a drastic drop of leakage current density of more than 5 orders of magnitude. The use of substrate biasing during PEALD is thereby a promising strategy for the improvement of AlN film quality.

KEYWORDS: aluminum nitride, PEALD, substrate biasing, ion energy, MIS capacitors, XPS

\section{INTRODUCTION}

With a structural crystallography close to that of gallium nitride $(\mathrm{GaN})$, aluminum nitride $(\mathrm{AlN})^{1}$ is an attractive material for GaN-based devices.

First, the direct epitaxial growth of $\mathrm{GaN}$ onto $\mathrm{Si}$ has to face a large mismatch between the lattice and the thermal expansion of both materials. ${ }^{2}$ Consequently, it induces critical strain in the $\mathrm{GaN} / \mathrm{Si}$ structures and leads to a large number of defects and possible cracks when cooling down after growth. Moreover, the GaN-on-Si growth may be hampered by the possible Ga/Si reaction that causes the so-called "melt-back". To bypass these critical issues, AlN is now commonly used as a nucleation layer to initiate the GaN growth. ${ }^{2}$ Furthermore, it has been observed that the growth of the AlN buffer layer and the III-V material in different reactors can improve the III-V crystal quality through the reduction of dislocations and strain. $^{3}$

Second, $\mathrm{AlN}$ is an attractive passivation layer for $\mathrm{GaN}$ since a high quality GaN/AlN interface can be formed. ${ }^{4-9}$ When this passivation layer precedes the dielectric gate deposition, both the AlN film quality and the AlN/GaN interface affect the characteristics of High Electron Mobility transistors (HEMTs) such as the electron mobility, charge trapping hysteresis, longterm reliability, and the threshold voltage. These ongoing issues represent a significant hurdle to overcome for the manufacturing of normally off HEMTs. ${ }^{2}$ Therefore, not only for GaN-on-Si epitaxy but also for $\mathrm{GaN}$ passivation, the growth of high AlN film quality is essential to enhance the performance of GaN-based devices.

The Plasma-Enhanced Atomic Layer Deposition (PEALD) is an emerging technique for the growth of aluminum nitride. It involves a self-limiting growth mechanism that enables the formation of high quality, conformal, and homogeneous films at the nanoscale. Besides, contrary to Metal Organic Chemical Vapor Deposition technique (MOCVD), PEALD is a low temperature process (typically $300{ }^{\circ} \mathrm{C}$ ) which allows further device integration. AlN growth using PEALD has been widely reported. Numerous parameters have been already investigated such as the type of ALD (thermal versus plasma), ${ }^{10,11}$ growth temperature, ${ }^{12}$ plasma duration, ${ }^{12}$ plasma chemistry, ${ }^{13-18}$ and plasma sources. ${ }^{19}$

PEALD is often used via a unique plasma source (for instance inductive or capacitive), which generates the ions and

Received: June 9, 2020

Accepted: August 10, 2020

Published: August 10, 2020 


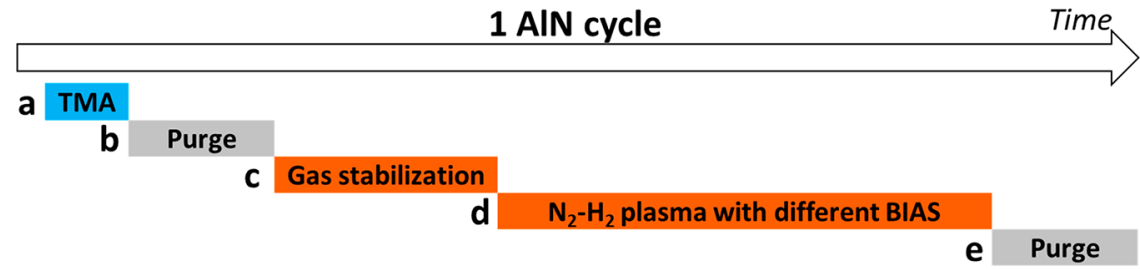

Figure 1. One AlN cycle.

radicals necessary for the film growth. Since this date, only a few groups have investigated the effect of substrate biasing during the plasma via an additional power supply. Kim et al. $^{20,21}$ have shown an increase in free radicals and ions with substrate biasing, leading to an enhancement of $\mathrm{HfO}_{2}$ dielectric properties. Kessels' group ${ }^{22-27}$ has thoroughly studied the effect of substrate biasing for several materials: $\mathrm{Al}_{2} \mathrm{O}_{3}, \mathrm{Co}_{3} \mathrm{O}_{4}$, $\mathrm{TiO}_{x}, \mathrm{TiN}_{x}, \mathrm{HfO}_{x}, \mathrm{HfN}_{x}, \mathrm{SiO}_{x}$, and $\mathrm{SiN}_{x}$. They highlighted that, by properly tuning the ion energy and dose via substrate biasing, it is possible to tailor the film properties such as mass density, refractive index, residual stress, and electrical properties. They also observed a modification of the crystallographic structure of $\mathrm{TiO}_{2}$, from anatase to rutile, using bias. ${ }^{22}$ According to Ratzsch et al., ${ }^{28}$ bias influences the nucleation and can also reduce the surface roughness of $\mathrm{TiO}_{2}$ film. Therefore, substrate bias during plasma may be a promising technique to enhance AlN film properties. As far as we know, this method was not studied for AlN.

In this work, we report a systematic study of the bias effect on the AlN film properties grown by PEALD on a silicon substrate. We show that the film quality and the dielectric properties can be greatly enhanced within a narrow substrate biasing window.

\section{EXPERIMENTAL SECTION}

(100) silicon wafers from Silicon Materials Inc. were used for all coatings. These wafers displayed a p-type doping with a resistivity in the range of $10-20 \mathrm{ohm} \cdot \mathrm{cm}$.

An Oxford instruments FlexAL reactor was employed for the growth of aluminum nitride. This particular equipment consists of two radiofrequency $(\mathrm{RF})$ power supplies of $13.56 \mathrm{MHz}$. The first one, connected to a coil wrapped around an alumina tube, generates the remote inductively coupled plasma (RF-ICP) and provides the ions and radicals necessary for the nitridation. A second additional power supply is connected to the substrate holder and allows bias of the substrate up to $100 \mathrm{~W}$. Trimethylaluminum from PURATREM (TMA, 99.99\%) and a $\mathrm{N}_{2}-\mathrm{H}_{2}$ gas mixture (ALPHAGAZ, 99.9999\%) were used as $\mathrm{Al}$ and $\mathrm{N}$ precursors, respectively. The gas flow was set at 20 and $10 \mathrm{sccm}$ for $\mathrm{N}_{2}$ and $\mathrm{H}_{2}$, respectively. This tool is also equipped with an in situ ellipsometer (SE) with four wavelengths (463, 524, 596 , and $634 \mathrm{~nm}$ ), allowing to continuously track the AlN growth. To do so, a three-layer model, consisting of AlN layer over native $\mathrm{SiO}_{2}$ over $\mathrm{Si}$ substrate, was built with the help of Film Sense Software. The refractive index and the extinction coefficient used for each material were tabulated optical constant files from the Film Sense software database. The only fitting parameter was the AlN thickness. From that, a nonlinear regression algorithm (Marquardt-Levenberg) iteratively adjusted this fitting parameter by minimizing the difference between the experimentally measured data and the modeled data.

Thin lamellae were prepared with a Focus Ion Beam Scanning Electron Microscope (FIB-SEM) tool (Helios Nanolab 450S from FEI). First, a protective platinum $(\mathrm{Pt})$ layer was deposited at sample surface using in situ gas injection systems (GIS) with an electron and ion beams. Small Pt particles were obtained using the electron beam resulting in smoother milling conditions during the thinning of the lamella. The lamellae were separated from the bulk using a cut with three rectangle patterns and were transferred to a Scanning Transmission Electron Microscopy (STEM) grid using in situ micromanipulator. Then, the lamellae were thinned to $\sim 100 \mathrm{~nm}$ using the ion beam with a voltage range from $2 \mathrm{kV}$ to $30 \mathrm{kV}$, with different beam currents between $0.021 \mathrm{nA}$ and $2.5 \mathrm{nA}$ and with several sample tilts. At the last step of the lamella preparation, a low voltage of $2 \mathrm{kV}$ and a low current of $21 \mathrm{pA}$ were used to reduce the amorphous layer on both sides of the lamella. Then, the structural properties were characterized in cross-section by STEM based on a field emission-gun (FEG) electron source across these thin lamellae. The FIB-STEM images were directly realized under the SEM column at $29 \mathrm{keV}$ to get spatial resolution in the range of $1 \mathrm{~nm}$. All layer observations were taken in the $[110]$ zone axis.

Systematic X-ray photoelectron spectroscopy (XPS) was performed to study the effect of the applied bias on the chemical composition of the AlN film. A Thermo Fisher Scientific Theta 300 was used with monochromatized $\mathrm{Al}-\mathrm{K} \alpha$ source, a beam size of $400 \mu \mathrm{m}$ and a pass energy of $100 \mathrm{eV}$. Moreover, the parallel Angle Resolved capability of this equipment (pAR-XPS) allowed us to simultaneously acquire eight angles, ranging from $23.75^{\circ}$ to $76.25^{\circ}$ (regarding the substrate normal), without tilting the sample and in only one acquisition. This angular resolution allows for probing the film at different depths and thereby estimating the layer thicknesses, such as the AlN native oxide over the AlN layer. In order to get a better charge stability, an electron flood gun was used. Data analysis was realized via ThermoFisher Avantage software. All spectra were shifted regarding the $\mathrm{C}-\mathrm{C}$ binding energy that was set at $285.0 \mathrm{eV}$.

Grazing Incidence X-ray Diffraction (GIXRD) acquisitions were carried out on a RIGAKU Smartlab equipped with a $9 \mathrm{~kW}$ rotating anode $\mathrm{Cu}$ source $(45 \mathrm{kV}$ and $200 \mathrm{~mA})$. The divergence thin film collimator was set at $0.5^{\circ}$ while the Omega incidence was $0.4^{\circ}$. Scans were realized between $20^{\circ}$ and $90^{\circ}$ (in $2 \theta$ scale) with a step of $0.06^{\circ}$ at $0.5^{\circ} / \mathrm{min}$.

AFM measurements were carried out on a Bruker Dimension ICON system in tapping mode using VTESPA-300 probes.

Auger electron spectroscopy (AES) is performed with a PHI 700Xi scanning Auger nanoprobe equipped with a cylindrical mirror analyzer $(\Delta E / E=0.5 \%)$ and a coaxial electron gun, normal to the sample. The electron beam energy and current were fixed at $10 \mathrm{keV}$ and $10 \mathrm{nA}$. The analyzed area was $100 \mu \mathrm{m}^{2}$. Depth profiling was performed at a grazing incidence $\left(28^{\circ}\right)$ with argon ions accelerated at $2 \mathrm{keV}(\sim 1 \mu \mathrm{A}$ current).

For the fabrication of capacitors, native silicon dioxide was removed via HF treatments. Right after, samples were loaded in the PEALD reactor to deposit the AlN film. After growth, patterns of the future capacitors were defined in a standard AZ1512HS positive photoresist using SUSS MicroTec MJB4 UV-visible lithography. Then, $30 \mathrm{~nm}$ of nickel and $100 \mathrm{~nm}$ of gold were e-beam evaporated in a MEB550 tool from PLASSYS. Finally, to reveal the contacts, the surplus of metal was lifted off in acetone. Capacitance-voltage characterizations were performed using Keithley 4200A SCS analyzer from $2 \mathrm{~V}$ to $-2.5 \mathrm{~V}$ with a step size of $-0.05 \mathrm{~V}$ and a frequency of 10 $\mathrm{kHz}$.

\section{RESULTS AND DISCUSSION}

PEALD Growth Conditions. One cycle of AlN consisted of five main steps as shown in Figure 1: (a) TMA injection (0.050 s), (b) Ar purge (3 s), (c) gas stabilization using a $\mathrm{N}_{2}-$ 

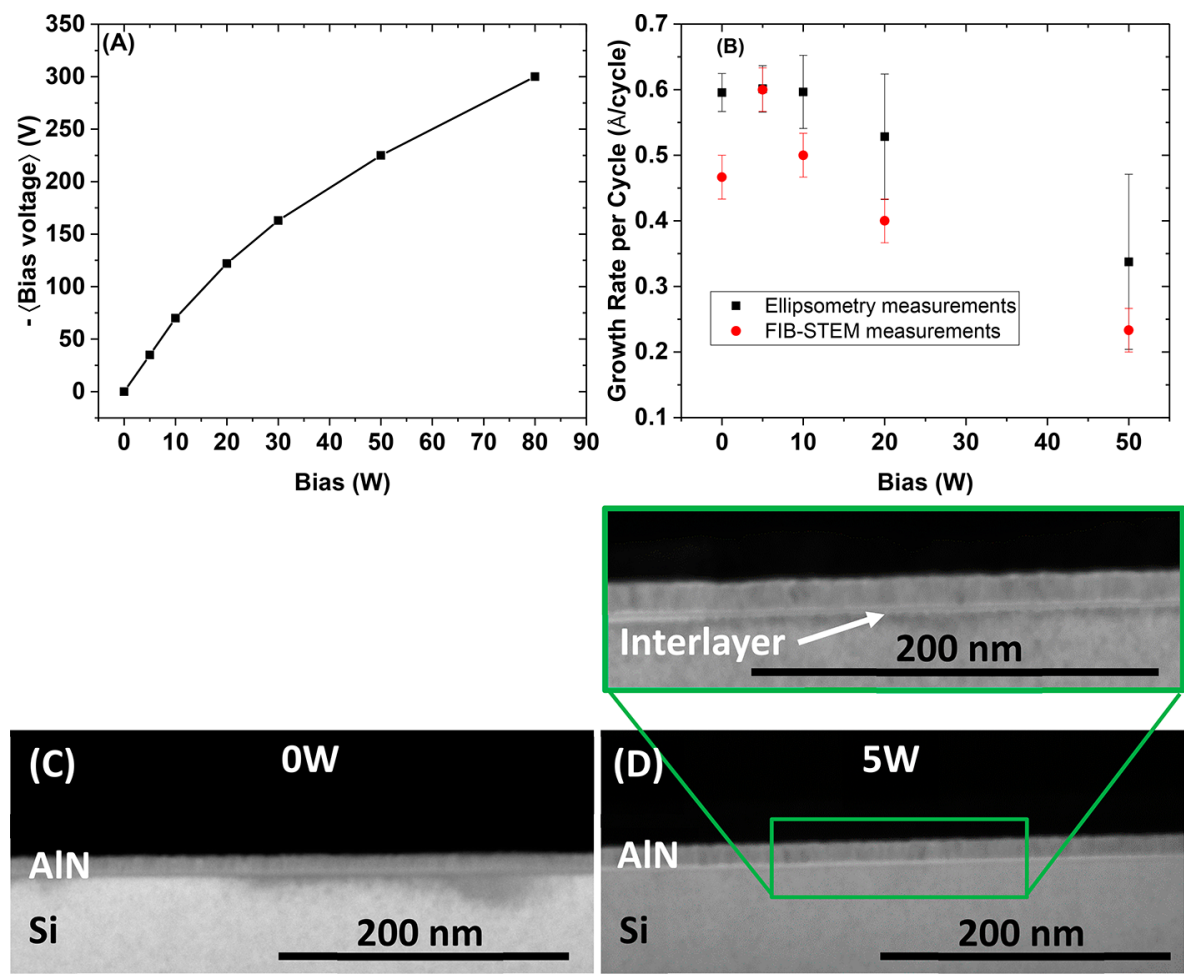

Figure 2. (A) Evolution of the average bias voltage (〈bias voltage $\rangle$ ), measured by the FlexAL equipment, as a function of the bias power. (B) Growth rate Per Cycle (GPC) as a function of bias assessed by in situ ellipsometry and by FIB-STEM measurements. FIB-STEM images used for the GPC estimation of AlN films deposited with a bias of (C) $0 \mathrm{~W}$ and (D) $5 \mathrm{~W}$. A higher magnification is depicted for (D) to highlight the formation of a brighter interlayer. The thicknesses were estimated at 14 and $18 \mathrm{~nm}$ for films deposited at $0 \mathrm{~W}$ and $5 \mathrm{~W}$, respectively. The images at higher biases $(10 \mathrm{~W}, 20 \mathrm{~W}$, and $50 \mathrm{~W}$ ) are available in the SI (Figure S1). For these images, the number of AlN cycles was set at 300.

$\mathrm{H}_{2}$ mixture with $33 \%$ of hydrogen ( $1.5 \mathrm{~s}$ ), (d) $\mathrm{N}_{2}-\mathrm{H}_{2}$ plasma ( 5 or $15 \mathrm{~s}$ ) at a pressure of $10 \mathrm{mTorr}$, and (e) Ar purge (3 s).

During the plasma, the RF-ICP power was fixed at $300 \mathrm{~W}$ with a chamber pressure of $10 \mathrm{mT}$ Torr. The temperature was set at $300{ }^{\circ} \mathrm{C}$, as commonly used in the literature. ${ }^{5,7,9,12,29-34}$

Role of Substrate Biasing during PEALD. The role of substrate biasing during PEALD was thoroughly described by Faraz et al. $^{26,27}$ Briefly, the RF-ICP plasma source generates the ions and radicals necessary for the nitridation and controls the ion flux reaching the substrate surface. In the remote configuration, the plasma, at a potential $V_{\mathrm{p}}$, is located away from the substrate table at a potential $V_{\text {substrate }}$. Due to the difference in mobility between the electrons and ions, a space charge region, the sheath $\left(\Delta V_{\text {sheath }}\right)$, is formed between the plasma and the substrate. At low pressure as it is the case here (10 mTorr), the ion mean free path is larger than the sheath thickness, the ions can pass through the sheath without undergoing any collisions and induce the phenomenon called ion bombardment on the substrate surface. In this collisionless plasma configuration, the ion energy $E_{\mathrm{i}}$ is directly proportional to this difference of potential as $E_{\mathrm{i}}=q \Delta V_{\text {sheath }}=q\left(V_{\mathrm{p}}-\right.$ $\left.V_{\text {substrate }}\right)$, where $q$ is the ion charge. In our FlexAL reactor, the additional power supply connected to the substrate allows to tune $V_{\text {substrate }}$ and thereby control the energy of ions that impinges on the substrate surface. ${ }^{26}$ Figure $2(\mathrm{~A})$ represents the evolution of the average bias voltage (〈bias voltage $\rangle$ ), measured by the FlexAL equipment, as a function of the bias power in our plasma conditions. As expected, the absolute value of the average bias voltage increases when the applied bias (power) increases. Therefore, knowing that $V_{\text {substrate }}=$ $-\langle$ bias voltage $\rangle,{ }^{26}$ the ion energy will increase with the applied bias. Notice that the samples were named, in the whole article, according to the applied bias power, which strongly depends on the specific plasma system. Thus, Figure 2(A) allows to extract the average bias voltage for a given applied bias power.

AIN Growth. Figure 2(B) illustrates the influence of substrate biasing on the growth rate per cycle of AlN (GPC) measured by ellipsometry and FIB-STEM. First, according to ellipsometry measurements, the GPC is in the range of 0.55$0.6 \AA /$ cycle for AlN deposited without substrate biasing, which is in agreement with typical values reported in the literature. ${ }^{13,15,17}$ When varying the bias, two different trends are highlighted: a GPC stagnation at low biases, then a monotonic decrease beyond $10 \mathrm{~W}$. At low biases, the low ion energy does not seem to influence the AlN growth whereas a strong GPC degradation is further observed. Similar results were observed for the growth silicon oxide or titanium nitride at high biases. ${ }^{26}$ This GPC decrease may arise from two phenomena: (i) surface damages and (ii) removal of reactive sites due to high ion bombardment. In Figure 2(B), we also estimated GPC by FIB-STEM techniques of AlN films deposited with 300 cycles, allowing an accurate measurement of AlN film thickness. It is important to mention that ellipsometry measurements and FIB-STEM analysis were carried out on AlN films deposited on native $\mathrm{SiO}_{2} / \mathrm{Si}$ and on HF-last $\mathrm{Si}$, respectively. Therefore, due to different surface terminations and thereby possible variation of AlN nucleation, straight comparison cannot be realized. However, in Figure 2(B), both GPC measurements exhibit close values and similar trend with substrate biasing. Notice that, from $0 \mathrm{~W}$ to $5 \mathrm{~W}$, GPC increases and this can be explained by the formation of an interfacial layer. Indeed, a brighter layer is visible when AlN 

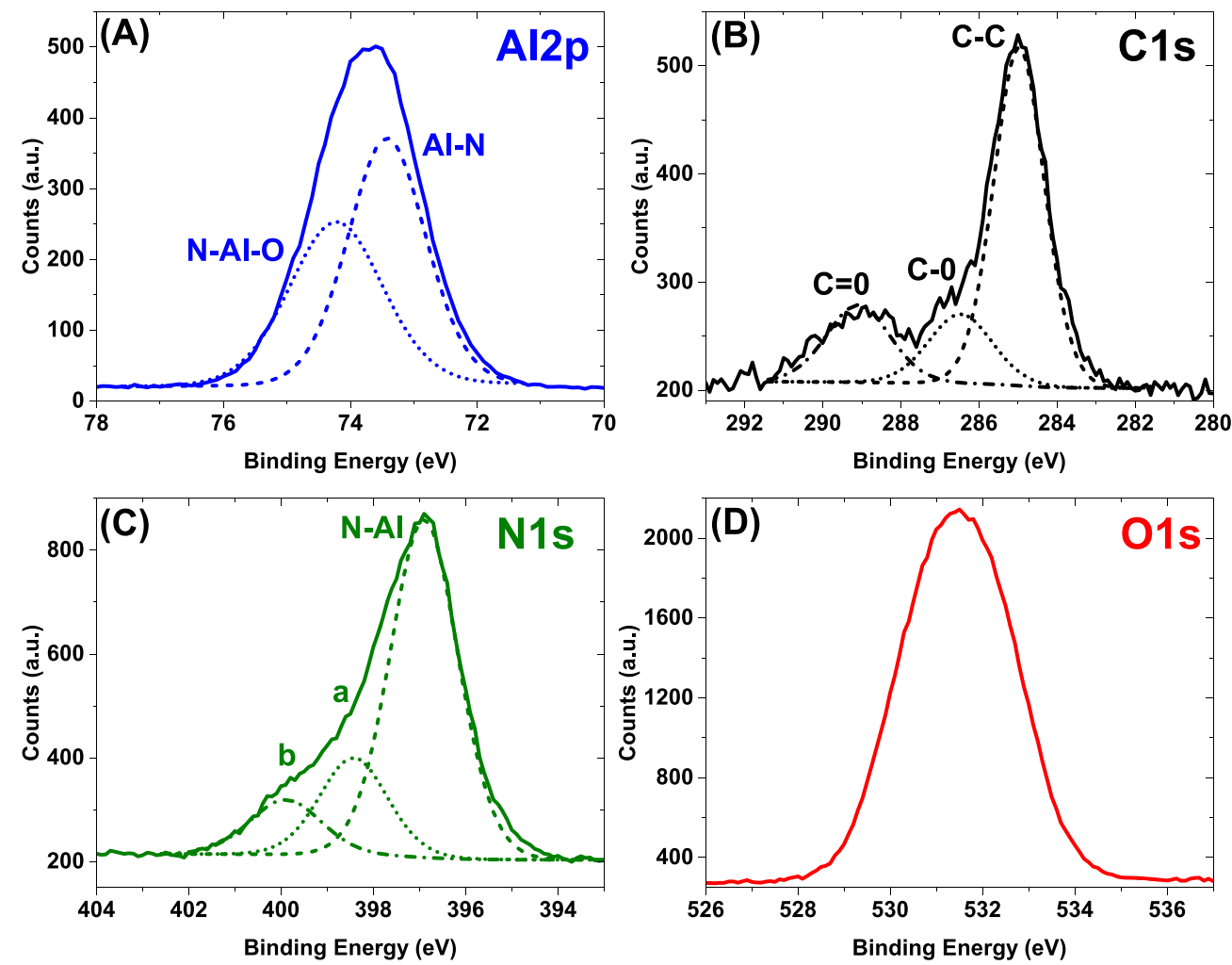

Figure 3. (A) $\mathrm{Al} 2 \mathrm{p},(\mathrm{B}) \mathrm{C} 1 \mathrm{~s}$, (C) $\mathrm{N}$ 1s, and (D) O 1s XPS spectra taken with a takeoff angle of $23.75^{\circ}$ for AlN sample deposited without bias.
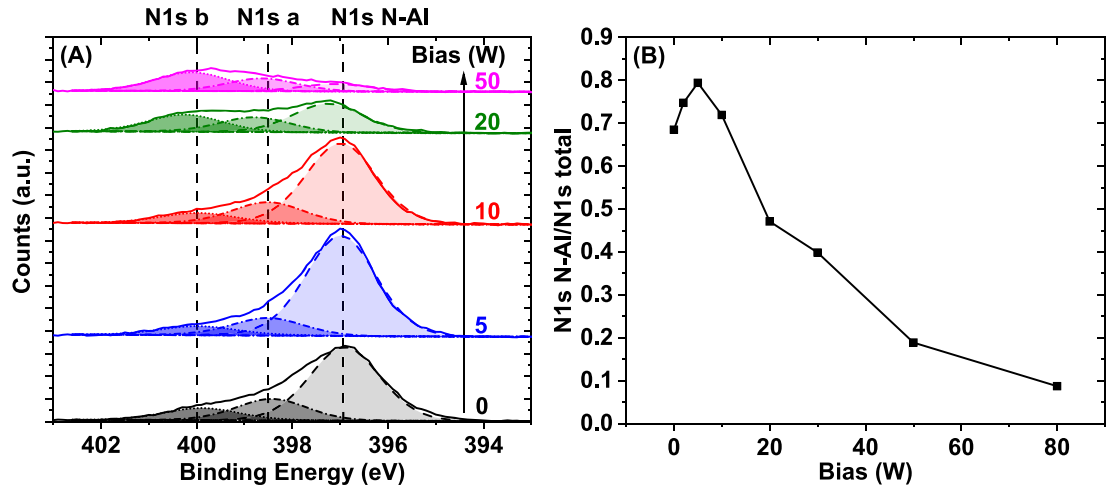

Figure 4. Bias effect on the $\mathrm{N}$ 1s chemical environment. (A) N 1s XPS spectra for different applied biases. (B) Atomic percentage ratio of N 1s N$\mathrm{Al}$ over the total of $\mathrm{N} 1 \mathrm{~s}$ as a function of applied bias. The measurement angle is $23.75^{\circ}$.

was deposited with $5 \mathrm{~W}$ (Figure 2(D)) compared to the one obtained without substrate biasing (Figure 2(C). Other FIBSTEM images at higher biases $(10 \mathrm{~W}, 20 \mathrm{~W}$, and $50 \mathrm{~W})$ are available in the SI (Figure S1). This interfacial layer likely comes from a nitridation of silicon surface that simultaneously takes place during the initial $\mathrm{N}_{2}-\mathrm{H}_{2}$ plasma steps when a bias is applied. To conclude, as the GPC is bias dependent, the number of AlN cycles is indicated for each following study instead of the AlN thickness.

Chemical Composition of AIN Films. The XPS core level of $\mathrm{Al} \mathrm{2p}, \mathrm{C} 1 \mathrm{~s}, \mathrm{~N} 1 \mathrm{~s}$, and $\mathrm{O} 1 \mathrm{~s}$ peaks recorded for AlN film deposited without bias are respectively shown in Figure 3(AD). For $\mathrm{Al} 2 \mathrm{p}$ (Figure 3(A)), two components are identified at 73.4 and $74.2 \mathrm{eV}$ corresponding to $\mathrm{Al}-\mathrm{N}$ bonds and native oxide $\mathrm{N}-\mathrm{Al}-\mathrm{O}$ bonds, respectively. The energy separation between these compounds is found to be $0.8 \mathrm{eV}$ which is consistent with values reported in the literature. ${ }^{35-37}$ The $\mathrm{N} 1 \mathrm{~s}$ spectrum consists of three components as illustrated in Figure $3(\mathrm{C})$. The main component, related to $\mathrm{N}-\mathrm{Al}$ bonds, is centered at $396.9 \mathrm{eV}$, which is close to the binding energy reported in the literature. ${ }^{37,38}$ However, $\mathrm{N}$ 1s spectrum also displays two other chemical environments noted "a" and " $b$ " which might be attributed to $\mathrm{N}-\mathrm{Al}-\mathrm{O}$ at $398.4 \mathrm{eV}$, $^{36,38}$ which is consistent here with $\mathrm{Al} 2 \mathrm{p}$, and unbonded $\mathrm{N}-\mathrm{N}$ at 399.9 $\mathrm{eV}^{39,40}$ Both contributions, the $\mathrm{Al} 2 \mathrm{p} \mathrm{Al}-\mathrm{N}$ and $\mathrm{N} 1 \mathrm{~s} \mathrm{~N}-\mathrm{Al}$ with a binding energy separation of $323.5 \mathrm{eV}$, confirm the proper formation of AlN. ${ }^{37,39}$ The C 1 s spectrum depicted in Figure 3(B) was deconvoluted into three contributions $\mathrm{C}-\mathrm{C}$, $\mathrm{C}-\mathrm{O}$, and $\mathrm{C}=\mathrm{O}$, arising from typical carbon contamination from the environment. Due to the complex $\mathrm{O} 1 \mathrm{~s}$ chemical environment (Figure 3(D)), the different contributions were not distinguished. However, the $\mathrm{O} 1 \mathrm{~s}$ spectrum is mainly attributed to surface hydroxide and AlN native oxide ${ }^{39,41}$ and contamination carbon. All these chemical environment assign- 
ments are in good agreement with the various vibrated molecules found in the Fourier Transform Infrared Spectroscopy (FTIR) absorption spectrum (see Figure S2 in the SI). It clearly confirms the proper formation of AlN and the presence of AlN oxide as well as unbonded N-N. In addition, it indicates a few numbers of carbon impurities, whereas some residues of hydrogen assigned to $\mathrm{Al}-\mathrm{NH}_{2}$ may remain. Besides, we also carried out XPS analysis on AlN layers deposited with different plasma chemistries: pure $\mathrm{N}_{2}, \mathrm{~N}_{2}-\mathrm{H}_{2}$ mixture with $17 \%$ and $33 \%$ of $\mathrm{H}_{2}$ (see Figure $\mathrm{S} 3$ in the SI). Note that the total flow remained at $30 \mathrm{sccm}$ to set the residence time of gases in the chamber, and no substrate biasing was applied. Poor AlN film quality was achieved with pure $\mathrm{N}_{2}$ plasma as the film mainly contained unbonded $\mathrm{N}-\mathrm{N}$ and $\mathrm{N}-\mathrm{Al}-\mathrm{O}$ bonds. On the contrary, the addition of $\mathrm{H}_{2}$ in the plasma significantly improved the AlN film quality, which increases with the concentration of $\mathrm{H}_{2}$. As a consequence, $\mathrm{H}_{2}$ is essential to achieve a good AlN film quality.

From the XPS analysis without bias, we deeply investigated the substrate biasing effect on the chemical composition of AlN films, as shown in Figure 4(A) for N 1s environment. One can notice a drastic influence of the bias on the $\mathrm{N} 1 \mathrm{~s}$ environment, when varying it from $0 \mathrm{~W}$ to $50 \mathrm{~W}$. For a better understanding, Figure 4(B) presents the atomic percentage ratio between the $\mathrm{N} 1 \mathrm{~s} \mathrm{~N}-\mathrm{Al}$ over the total of $\mathrm{N} 1 \mathrm{~s}$ for different biases. This ratio first increases from 0.68 to 0.8 when the bias varies from $0 \mathrm{~W}$ to $5 \mathrm{~W}$ and then, beyond $5 \mathrm{~W}$, it drops significantly. It suggests an enhancement of the AlN film quality at low biases due to the formation of more $\mathrm{N}-\mathrm{Al}$ bonds followed by the layer degradation for higher biases. Therefore, a bias power window between $2 \mathrm{~W}$ and $10 \mathrm{~W}$ appears for AlN growth. (i) From $0 \mathrm{~W}$ to $5 \mathrm{~W}$, the bias power provides the energy needed for ions to improve the nitridation and thereby the AlN film quality. According to Faraz et al., ${ }^{27}$ it is related to the material atom displacement or activation of ion-induced chemical reaction. (ii) For a bias power close to but somewhat higher than $5 \mathrm{~W}$, a competition between nitridation and ion bombardment occurs. In this bias range, AlN quality is reduced compared to film deposited at $5 \mathrm{~W}$ but is still higher than the layer deposited without bias. (iii) Finally, at higher biases ( $>10$ $\mathrm{W}$ ), a further increase of ion energy induces an important AlN degradation due to the too high bombardment. It is worth emphasizing that similar trends were observed for AlN films five times thicker, suggesting a homogeneous AlN layer within the bulk (see Figure S4 in the SI). In addition, shorter plasma (5 s duration) was also investigated for different biases (see Figure S4 in the SI). Notice that bias was again applied during the whole plasma duration ( $5 \mathrm{~s}$ ). For shorter plasma durations, a poor number of $\mathrm{N}-\mathrm{Al}$ bonds were formed as the atomic percentage ratios are close to 0 . Films mainly consisted of $\mathrm{N}-$ $\mathrm{Al}-\mathrm{O}$ bonds and unbonded $\mathrm{N}-\mathrm{N}$. Moreover, there was no clear evolution of atomic percentage ratios with substrate biasing, except for $10 \mathrm{~W}$. These results show that, due to the too short plasma duration, the ion dose was not sufficiently high to efficiently nitride the substrate surface. Therefore, longer plasma duration, and therefore higher ion dose (as used in this paper), is essential to allow an efficient nitridation and to fully benefit from the bias effect.

In addition to the previous study, we used the parallel angle resolved capability of the XPS equipment to investigate the bias effect on the $\mathrm{Al} 2 \mathrm{p}$ chemical environment. pAR-XPS allows us not only to improve the reliability of the measurement, but also to provide a chemical depth profile from computation of the angle resolved data. ${ }^{42}$ Interestingly, for a bilayer film, the overlayer thickness can be easily extracted using only the electron attenuation length and the evolution of peak area ratios for different measurement angles. ${ }^{43}$ It is important to notice that this widely used XPS thickness measurement is improved here thanks to pAR-XPS. Indeed, the thickness is extracted from one peak's ratio and from the slope of the angular response of the ratios for different angles. This leads to a better reproducibility and robustness of the thickness measurement. ${ }^{42}$ Moreover, the good alignment of the angular response here allows us to confirm the presence of a conformal $\mathrm{Al}$ oxide layer on the AlN substrate, as well as the correct attribution of the $\mathrm{N}-\mathrm{Al}-\mathrm{O}$ and $\mathrm{Al}-\mathrm{N}$ components on the spectra. To do that, the densities of both layers have to be supposed for the calculation of the electron attenuation length using the Cumpson-Seah model. ${ }^{43}$ In our case, because of the presence of two $\mathrm{Al} 2 \mathrm{p}$ contributions $\mathrm{N}-\mathrm{Al}-\mathrm{O}$ and $\mathrm{Al}-\mathrm{N}$, we can fairly assume that the films are a bilayer composed of a native oxide over an AlN layer, respectively. The AlN native oxide was considered as alumina with a density of $3.97 \mathrm{~g} \cdot \mathrm{cm}^{-3}$ and the AlN density was set at $3.3 \mathrm{~g} \cdot \mathrm{cm}^{-3}$. From these densities, the electron attenuation length was $22.2 \AA$. Then, the equivalent AlN oxide thickness was estimated for the different substrate biasing as represented in Figure 5. One can notice

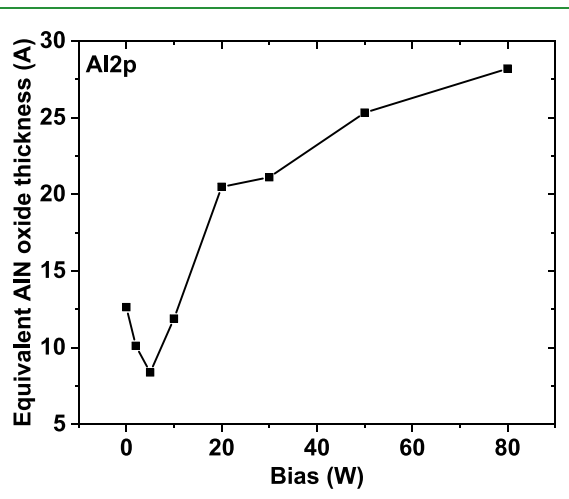

Figure 5. Bias effect on the equivalent AlN oxide thickness. For this estimation, a bilayer composed of a native oxide over AlN layer is assumed based on the $\mathrm{Al} 2 \mathrm{p}$ chemical environment. The AlN native oxide is considered as alumina with a density of $3.97 \mathrm{~g} \cdot \mathrm{cm}^{-3}$, and the AlN density is set at $3.3 \mathrm{~g} \cdot \mathrm{cm}^{-3}$. From these densities, the attenuation length of $22.2 \AA$ is calculated using the Cumpson-Seah model.

first a reduction of oxide thickness when the bias varies from 0 to $5 \mathrm{~W}$ and, beyond $5 \mathrm{~W}$, it significantly increases. This trend is consistent with the previous study for N 1s (Figure 4). Indeed, as more $\mathrm{N}-\mathrm{Al}$ bonds are formed at low bias, the AlN film becomes denser. Thus, it limits its oxidation in air with an optimum emerging again at $5 \mathrm{~W}$. For higher biases, the high ion bombardment may induce the formation of porosities and voids in the films, as observed in the literature, ${ }^{26}$ that increases the AlN oxidation.

Auger Depth Profile. Figure 6 illustrates the Auger depth profiles of AlN films deposited using 500 cycles without and with substrate biasing of $5 \mathrm{~W}$ and $20 \mathrm{~W}$. Without substrate biasing (Figure 6(A)), the oxygen and carbon signals drop a few atomic percentages after only $1 \mathrm{~min}$ of etching. It first indicates that carbon and oxygen are mainly located on the surface due to carbon contamination and surface oxidation from ambient atmosphere after film deposition. This observation is confirmed by the pAR-XPS results previously 

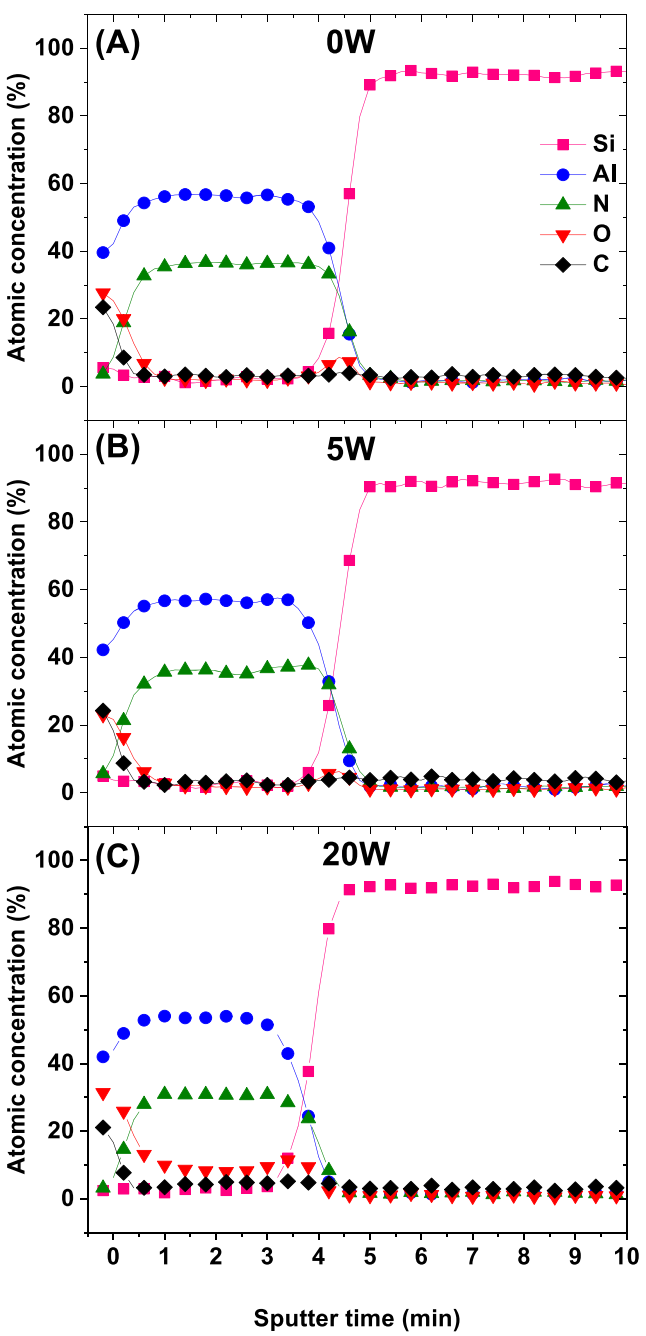

Figure 6. Auger depth profiles of AlN films deposited using 500 cycles (A) without and with substrate biasing of (B) $5 \mathrm{~W}$ and (C) $20 \mathrm{~W}$.

observed (Figure 5), showing the presence of an AlN native oxide. Second, the quick decrease of the oxygen and carbon signals demonstrates low carbon and oxygen impurities insertion within the AlN film elaborated without substrate biasing. Third, the presence of two plateaus for the nitrogen and aluminum signals highlights the AlN film composition is homogeneous across the layer. The lower nitrogen atomic percentage compared to that of aluminum suggests a deficiency in nitrogen. It might come from an excess of hydrogen residues in the film, as observed by FTIR characterizations (see Figure S2 in the SI). In addition, the quantification exhibits an important error of about $\pm 20 \%$, as the relative atomic percentages are calculated from tabulated sensitivity factors obtained on standards whose composition may differ from the analyzed samples. Similar trends were observed for AlN film elaborated at a substrate biasing of $5 \mathrm{~W}$ (Figure 6(B)). Contrary to the previous pAR-XPS analysis (Figure 4), the Auger depth profile does not allow us to highlight a clear difference between the $5 \mathrm{~W}$ and $0 \mathrm{~W}$ samples, which may originate from the important atomic percentage error. Finally, for the AlN film elaborated at a substrate biasing of $20 \mathrm{~W}$ (Figure 6(C)), one can notice the presence of oxygen contamination across the layer, which indicates an important oxidation of the film after deposition. The Auger depth profile clearly confirms that high ion bombardment at high substrate biasing leads to the formation of porosities and voids in the film that facilitates its oxidation.

Crystallographic Structure. Figure 7 illustrates the $\theta / 2 \theta$ $\mathrm{X}$-ray diffraction patterns of hexagonal AlN and the GIXRD

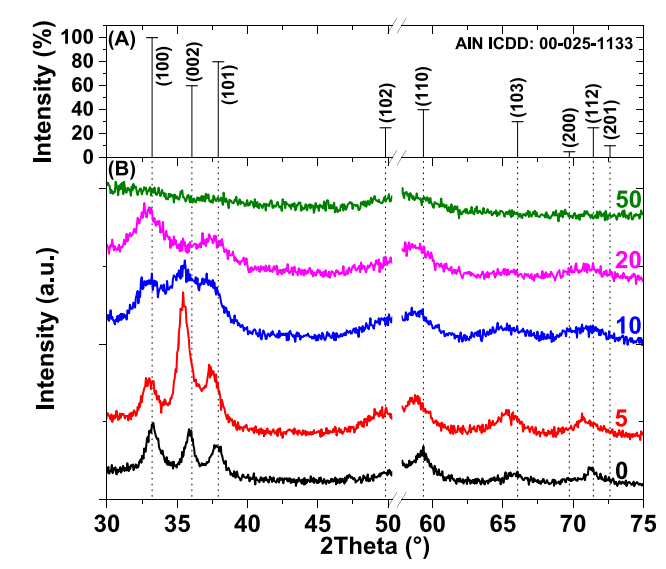

Figure 7. (A) $\theta / 2 \theta$ X-ray diffraction patterns of hexagonal AlN (ICDD: 00-025-1133). (B) GIXRD patterns of AlN samples deposited at different bias, indicated on the plot. The plasma duration was $15 \mathrm{~s}$ and the number of cycles, constant, was 500 .

patterns of AlN films deposited with 500 cycles at different biases. Without bias, the presence of six peaks highlights that films crystallize with a hexagonal wurtzite structure. In addition, no peaks shift regarding the ICDD hexagonal AlN pattern, resulting in cell parameters of $3.11 \AA$ for $a$ and $4.98 \AA$ for $c$. Although no preferential orientation can be deduced from GIXRD measurements, the (002) peak becomes the most intense for films deposited at $5 \mathrm{~W}$ compared to the one obtained without bias. Considering similar GPC (Figure 2) thereby similar film thickness, it may indicate a higher crystalline fraction using bias at $5 \mathrm{~W}$. The increase of the number of $\mathrm{N}-\mathrm{Al}$ bonds, previously shown in Figure 4, could account for this crystallinity enhancement at $5 \mathrm{~W}$. Then, the increase of bias reduces the intensity of peaks, which totally disappear at $50 \mathrm{~W}$. These results are again in agreement with the previous XPS analysis as it suggests a degradation of crystallinity and thereby film amorphization due to high ion bombardment. Moreover, it is worth mentioning that all peaks are shifted toward a lower angle when using bias during AlN deposition. Regarding the peak location of the $5 \mathrm{~W}$ sample, this shift suggests an increase from 3.11 to $3.14 \AA$ for $a$ and from 4.98 to $5.05 \AA$ for $c$. Interestingly, these values get thus closer to hexagonal GaN cell parameters, ${ }^{1}$ which brings interesting results for the further use of this AlN as a buffer layer of GaN epitaxy.

Topography. Topography of AlN films deposited with 300 cycles at different biases are shown in Figure 8. From $0 \mathrm{~W}$ to $10 \mathrm{~W}$, films display a low surface roughness which slightly increases from 0.6 to $0.7 \mathrm{~nm}$. However, for higher biases $(\geq 20$ $\mathrm{W})$, large randomly spread islands are formed that induce a significant increase of the roughness. In addition, their density, size, and height raise when increasing the bias. For the $20 \mathrm{~W}$ sample, there are roughly 6 islands $\mu \mathrm{m}^{-2}$ with a size of $70 \mathrm{~nm}$ and height of $10 \mathrm{~nm}$ while, for the $50 \mathrm{~W}$ one, there are roughly 8 islands $\mu \mathrm{m}^{-2}$ with a size of $110 \mathrm{~nm}$ and height of $16 \mathrm{~nm}$. Further analysis has to be performed for a better understanding of the island formation, which goes out of the scope of this article. However, it might come from the important surface 

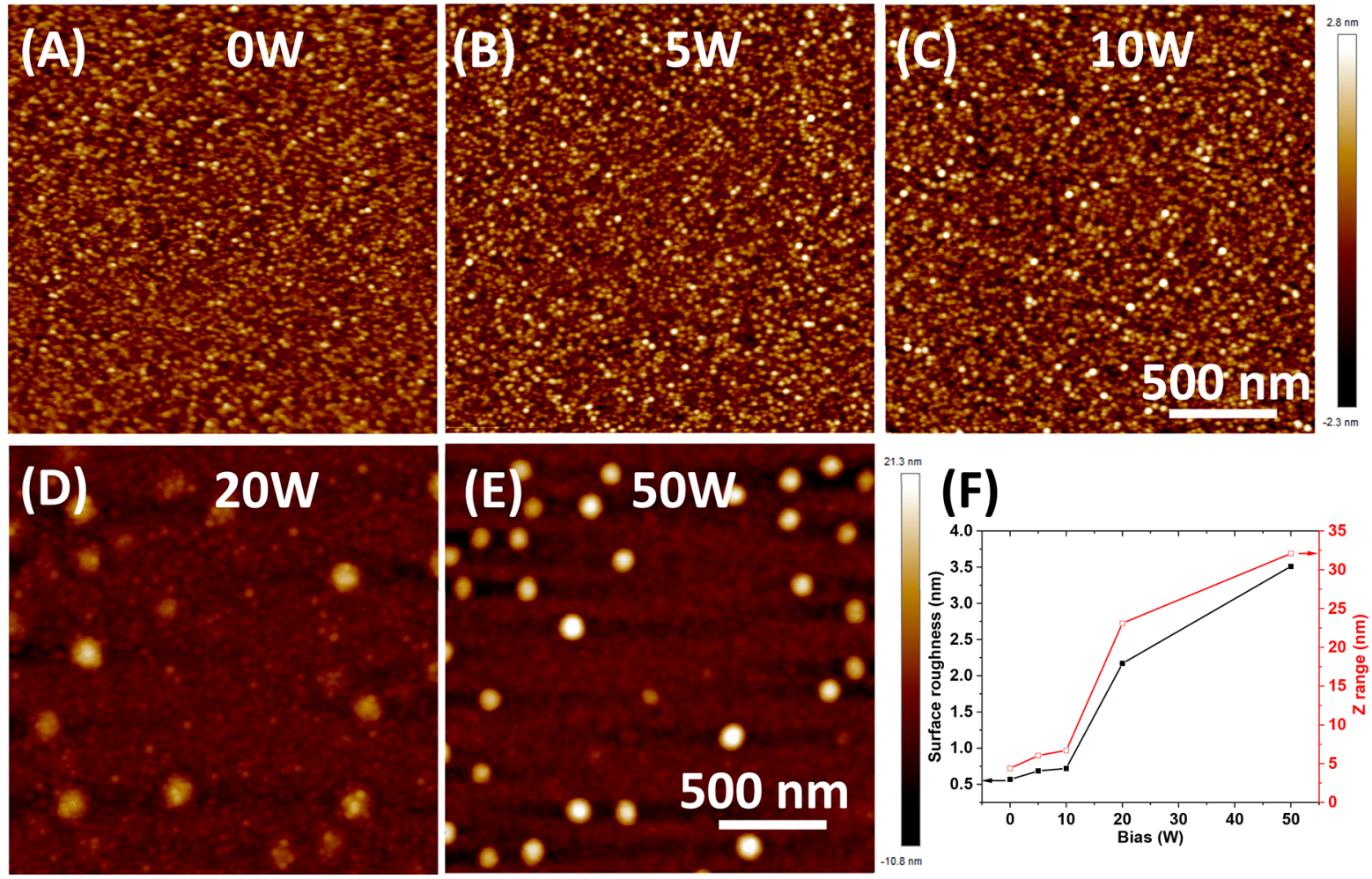

Figure 8. AFM images for different applied biases. The bias is indicated on the images. All these images present the same scale bar of $500 \mathrm{~nm}$, while the color bar is identical for $(\mathrm{A}-\mathrm{C})$ and for $(\mathrm{D}, \mathrm{E})$. (F) Surface roughness and $Z$ range as a function of bias estimated from the AFM images. Plasma duration was set at $15 \mathrm{~s}$, and the number of cycles, constant, was 300 .

damages and/or the onset void incorporation due to high ion bombardment. This effect has been observed for $\mathrm{TiO}_{2}$ growth using similar PEALD tool. ${ }^{26}$

Electrical Properties. Finally, the electrical properties of AlN films deposited on HF-last $\mathrm{Si}(100)$ at various biases were investigated with the help of back-to-back Metal-InsulatorSemiconductor (MIS) capacitors, as shown in Figure 9. In this
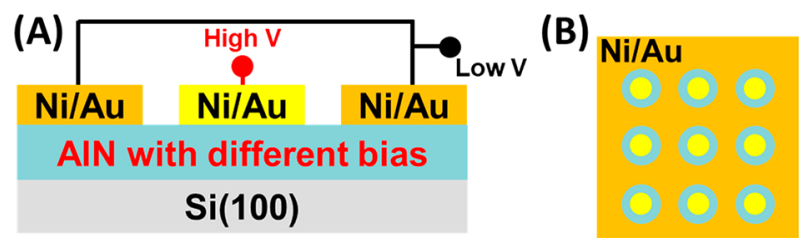

Figure 9. Schematic representation of one capacitance in (A) crosssectional view and (B) top view scheme of one chip with nine capacitors. The diameter of the capacitors was $600 \mu \mathrm{m}$.

configuration, there are two capacitances in series: one from the circular contact pad and another one roughly covering the whole chip (Figure 9(B)). Due to the difference of 2-3 orders of magnitude between the surface of both capacitances, the capacitance from the whole chip can be neglected over that from the circular contact pad, as previously reported. ${ }^{44}$ Thus, the high voltage probe was located on the circular contact pad and the other one, the low voltage, on large contact covering the chip.

Figure 10(A) illustrates the measured capacitance normalized by the maximal capacitance $\left(C / C_{\max }\right)$ versus voltage $(V)$, at $10 \mathrm{kHz}$, for AlN deposited at different biases with 300 cycles (the raw data of capacitance and leakage current density are available in SI Figure S5). Without bias, three different plateaus are visible when sweeping from negative to positive voltage: a first one at negative voltage, a second one at lower $C / C_{\max }$ value in the range of $0 \mathrm{~V}$, then a third one beyond $0.5 \mathrm{~V}$ where $C / C_{\max }$ is close to 0 . The first capacitance stagnation is a typical behavior for p-type MIS capacitors, attributed to the formation of an accumulation layer at the AlN-Si interface. In addition, the second plateau in the depletion region around 0 $\mathrm{V}$ highlights the presence of high trap density at the AlN-Si interface (Figure 10(A)). Finally, the last plateau in positive voltage value corresponds to the weak and strong inversion. Surprisingly, there is no increase of the capacitance in the inversion regime, whereas a relatively low frequency was used. It shows that the generation-recombination rate of electrons (minority carriers) cannot follow the applied ac signal. ${ }^{45}$ Similar results of AlN-based MIS capacitors were observed for AlN elaborated with magnetron sputtering, ${ }^{46,47}$ pulsed laser deposition, ${ }^{48}$ molecular beam epitaxy ${ }^{49}$ and MOCVD. ${ }^{50,51}$ According to the study by Adam et al. ${ }^{47}$ of AlN/p-type $\mathrm{Si}(100)$ MIS capacitors, the absence of minority carriers at low frequency may come from a large number of fast recombination centers at the $\mathrm{AlN} / \mathrm{Si}$ interface. Therefore, the absence of an inversion layer indicates a poor AlN/Si interface quality. On the contrary, capacitors with an AlN film deposited at $5 \mathrm{~W}$ exhibit a capacitance increase for positive voltage value, arising from the formation of electron inversion layer (Figure $10(\mathrm{~A}))$. It highlights an improvement of the AlN-Si interface through the reduction of recombination centers. In addition, according to the observations by FIB-STEM (Figure 2(D)), the interlayer, likely formed by Si nitridation during the initial plasma steps at $5 \mathrm{~W}$, allows us to get a high-quality interface with $\mathrm{Si}$. Note that $\mathrm{Bi}$ et al. ${ }^{52}$ and $\mathrm{Xi}$ et al. $^{53}$ reported the formation of inversion layer of AlN-based MIS capacitor, 

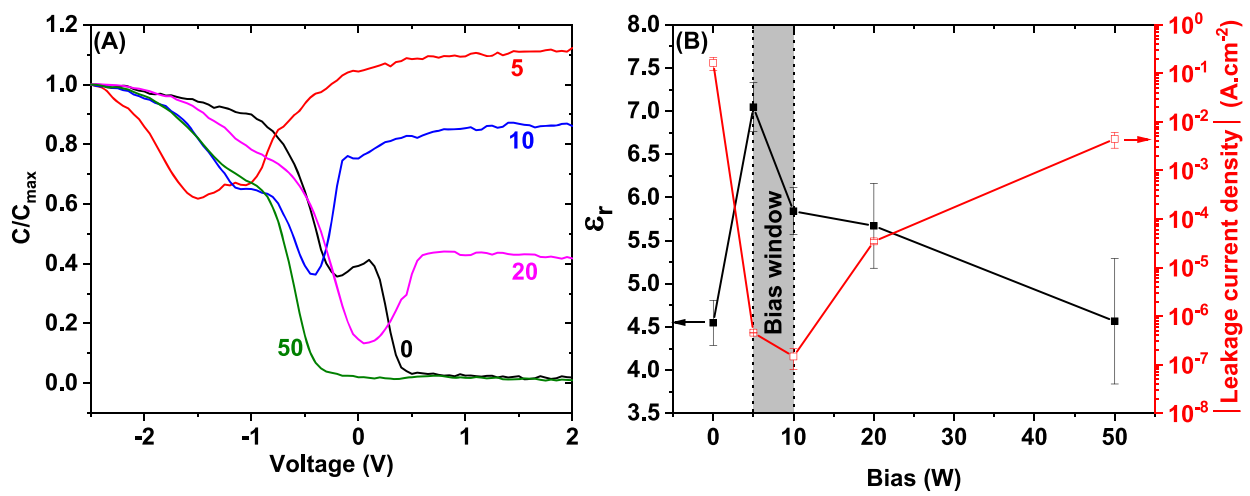

Figure 10. (A) Measured capacitance normalized by the maximal capacitance $\left(C / C_{\max }\right)$ versus voltage $(\mathrm{V})$. (B) Relative permittivity $\left(\varepsilon_{\mathrm{r}}\right)$ and maximal leakage current density for different bias. For $(\mathrm{A})$, the frequency was $10 \mathrm{kHz}$. $C_{\max }$ and maximal current density were extracted at $-2.5 \mathrm{~V}$. For the growth conditions, the plasma duration was set at $15 \mathrm{~s}$, and the number of cycles, constant, was 300 . The gray square highlights the narrow bias window required to enhance $\varepsilon_{\mathrm{r}}$ and reduce the maximal leakage current density.

however, for films deposited at high temperature (1050-1100 ${ }^{\circ} \mathrm{C}$ ) compared to $300{ }^{\circ} \mathrm{C}$ for our PEALD process. Finally, increasing the bias from $10 \mathrm{~W}$ to $20 \mathrm{~W}$ during AlN coating leads to a significant diminution of the capacitance in the inversion regime, which totally disappears for the $50 \mathrm{~W}$ sample, as well as for the $0 \mathrm{~W}$ film (Figure 10(A)). This result indicates a further increase of the recombination centers and thereby a degradation of the AlN/Si interface for higher biases than 10 W. Further $C-V$ characterizations at various frequencies will be required for a better understanding of the interface state traps.

Figure 10(B) illustrates the relative permittivity $\left(\varepsilon_{\mathrm{r}}\right)$ and the maximal leakage current density for different biases during AlN coating. Both parameters were extracted in the accumulation regime at $-2.5 \mathrm{~V}$. Indeed, the maximal capacitance $\left(C_{\max }\right)$ in this region is close to that of AlN, which leads to a AlN relative permittivity using the well-known equation $C_{\max }=\varepsilon_{0} \times \varepsilon_{\mathrm{r}} \times S$ / $t$ where $\varepsilon_{0}$ is the vacuum dielectric constant, $S$ the capacitor area, and $t$ the thickness. In order to have an accurate estimation of the relative permittivity, the thicknesses of deposited films, which are highly bias dependent, were measured on the FIB-STEM images, illustrated in Figures 2 and S1 (SI). In Figure 10(B), one can notice, first, an enhancement of $\varepsilon_{\mathrm{r}}$ from 4.5 to 7.0 when raising the bias from 0 $\mathrm{W}$ to $5 \mathrm{~W}$, and then a monotonic $\varepsilon_{\mathrm{r}}$ decrease for a further bias increase. Note that the optimum $\varepsilon_{\mathrm{r}}$ of $7.0 \pm 0.3$ obtained for AlN films at a bias of $5 \mathrm{~W}$ is close to the theoretical value of 8.5. ${ }^{54}$ In addition, the exact opposite trend is observed for maximal current density at different biases. It is worth emphasizing that the leakage current density drops by 5 orders of magnitude by varying the bias from $0 \mathrm{~W}$ to $5 \mathrm{~W}$, then it decreases slightly, from $5 \mathrm{~W}$ to $10 \mathrm{~W}$, with a value as low as $10^{-7} \mathrm{~A} \cdot \mathrm{cm}^{-2}$ while the AlN film thicknesses were similar, in the range of 14-18 $\mathrm{nm}$. Therefore, the drastic drop in leakage current arises from the deposited film properties, not from film thickness changes. One can notice that the evolution of both parameters, $\varepsilon_{\mathrm{r}}$ and maximal leakage current density, is in close connection with the XPS analysis. It proves that, at low biases $(5 \mathrm{~W}$ to $10 \mathrm{~W})$, the increase of relative permittivity and the reduction of leakage current density, not only arise from the improvement of film quality as more $\mathrm{N}-\mathrm{Al}$ bonds are formed, but also from the formation of a high-quality interfacial layer. A higher bias (higher energetic ions) degrades the AlN quality and therefore the electrical properties. Moreover, the AlN roughening at $20-50 \mathrm{~W}$ bias (Figure 8) may also account for the increase of leakage current density.

To conclude, we showed that the use of substrate biasing within a narrow window ( $5 \mathrm{~W}$ to $10 \mathrm{~W}$ ) allows for improving the $\mathrm{AlN} / \mathrm{Si}$ interface and the relative permittivity while drastically reducing the leakage current compared to film deposited without bias. Besides, we roughly assessed an average ion energy ranging from around 55 to $90 \mathrm{eV}$ in this bias range, on the basis of Faraz' work. ${ }^{27}$ Indeed, they measured the ion energy distribution for different substrate biasing using similar Oxford Instruments FlexAL reactor and relatively close plasma conditions (ICP power of $200 \mathrm{~W}$, chamber pressure of $9 \mathrm{mT}$ orr, plasma chemistry either of $\mathrm{N}_{2}$ or $\mathrm{H}_{2}$ ). Therefore, we demonstrated the importance of using ions at low energy to improve the AlN film quality. This work will provide guidance for the deposition of other materials deposited by PEALD.

\section{CONCLUSIONS}

Substrate biasing during the growth of AlN by PEALD on silicon substrate was investigated. In addition to conventional RF-ICP source, the PEALD reactor was equipped with another RF power supply connected to the substrate holder that allows us to tune the ion energy impinging the substrate surface. The carried-out characterizations (SE, pAR-XPS, GIXRD, AFM, $C-V$ ) highlight a narrow substrate biasing window, from $5 \mathrm{~W}$ to $10 \mathrm{~W}$ (from $-35 \mathrm{~V}$ to $-70 \mathrm{~V}$ ), in which the AlN properties were significantly improved compared to the film deposited without substrate biasing. Indeed, the electrical properties of the AlN film were clearly enhanced due to an increase of the relative permittivity and a drastic drop of the leakage current of more than 5 orders of magnitude. Besides, a high-quality interfacial layer was formed, with silicon, during the initial $\mathrm{N}_{2}-$ $\mathrm{H}_{2}$ plasma steps at low substrate biasing $(5 \mathrm{~W})$. Moreover, we also showed an improvement of the $5 \mathrm{~W}$ AlN film chemical composition through an increase of $\mathrm{N}-\mathrm{Al}$ bonds and a reduction of the AlN native oxide thickness. In addition, the use of bias in this window did not induce an important change of the GPC and the surface roughness. On the contrary, higher bias and therefore higher ion energy induces a degradation of film quality (GPC reduction, reduction of $\mathrm{N}-\mathrm{Al}$ bonds, roughening, amorphization, and reduction of electrical properties) due to the too high ion bombardment.

All these results, in close agreement, suggest that by providing a proper energy to ions via substrate biasing, it is 
possible to significantly promote the nitridation and therefore improve the film properties compared to films elaborated without bias. It also demonstrates the importance of using ions at low energy to improve the AlN film quality. The use of AlN films elaborated with bias PEALD, for instance as a buffer layer for $\mathrm{GaN}$ epitaxy or as $\mathrm{GaN}$ passivation layer for $\mathrm{GaN}$-based devices, will be interesting.

\section{ASSOCIATED CONTENT}

\section{SI Supporting Information}

The Supporting Information is available free of charge at https://pubs.acs.org/doi/10.1021/acsami.0c10515.

Additional FIB-STEM images at different biases; FTIR absorption spectrum of AlN film deposited without bias; plasma chemistry effect on N1 chemical environment; bias effect on the $\mathrm{N}$ 1s chemical environment for different plasma durations and AlN film thicknesses; and raw data of capacitances and leakage current density for AlN films elaborated at different substrate biasing (PDF)

\section{AUTHOR INFORMATION}

\section{Corresponding Authors}

Maxime Legallais - Universite Grenoble Alpes, CNRS, CEA/ LETI Minatec, LTM, F-38054 Grenoble, France; 이이. ord.org/ 0000-0002-7773-7479; Email: maxime.legallais@cea.fr

Bassem Salem - Université Grenoble Alpes, CNRS, CEA/LETI Minatec, LTM, F-38054 Grenoble, France; 이이.org/00000001-8038-3205; Email: bassem.salem@cea.fr

\section{Authors}

Hussein Mehdi - Université Grenoble Alpes, CNRS, CEA/ LETI Minatec, LTM, F-38054 Grenoble, France

Sylvain David - Université Grenoble Alpes, CNRS, CEA/LETI Minatec, LTM, F-38054 Grenoble, France

Franck Bassani - Université Grenoble Alpes, CNRS, CEA/LETI Minatec, LTM, F-38054 Grenoble, France; 이이이.org/00000001-8688-1328

Sébastien Labau - Université Grenoble Alpes, CNRS, CEA/ LETI Minatec, LTM, F-38054 Grenoble, France

Bernard Pelissier - Universite Grenoble Alpes, CNRS, CEA/ LETI Minatec, LTM, F-38054 Grenoble, France

Thierry Baron - Université Grenoble Alpes, CNRS, CEA/LETI Minatec, LTM, F-38054 Grenoble, France

Eugenie Martinez - Université Grenoble Alpes, CEA/LETI, MINATEC Campus, F-38054 Grenoble, France

Gérard Ghibaudo - Université Grenoble Alpes, CNRS, Grenoble INP, IMEP-LAHC, 38000 Grenoble, France

Complete contact information is available at: https://pubs.acs.org/10.1021/acsami.0c10515

\section{Notes}

The authors declare no competing financial interest.

\section{ACKNOWLEDGMENTS}

This work has received a partially funding from IPCEINano2022. This work benefited from the facilities and expertise of PTA (Upstream Technological Platform), cooperated by CNRS RENATECH and CEA Grenoble, France and has been partially supported by the EquipEx IMPACT program, managed by the ANR French agency (ANR-10EQPX-33). This work also benefits from the facilities and expertise of the OPE)N(RA characterization platform of FMNT (FR2542, supported by CNRS, Grenoble INP, UGA).

\section{REFERENCES}

(1) Wright, A. F.; Nelson, J. S. Consistent Structural Properties for AlN, GaN, and InN. Phys. Rev. B: Condens. Matter Mater. Phys. 1995, 51 (12), 7866-7869.

(2) Amano, H.; Baines, Y.; Beam, E.; Borga, M.; Bouchet, T.; Chalker, P. R.; Charles, M.; Chen, K. J.; Chowdhury, N.; Chu, R.; De Santi, C.; De Souza, M. M.; Decoutere, S.; Di Cioccio, L.; Eckardt, B.; Egawa, T.; Fay, P.; Freedsman, J. J.; Guido, L.; Häberlen, O.; Haynes, G.; Heckel, T.; Hemakumara, D.; Houston, P.; Hu, J.; Hua, M.; Huang, Q.; Huang, A.; Jiang, S.; Kawai, H.; Kinzer, D.; Kuball, M.; Kumar, A.; Lee, K. B.; Li, X.; Marcon, D.; März, M.; McCarthy, R.; Meneghesso, G.; Meneghini, M.; Morvan, E.; Nakajima, A.; Narayanan, E. M. S.; Oliver, S.; Palacios, T.; Piedra, D.; Plissonnier, M.; Reddy, R.; Sun, M.; Thayne, I.; Torres, A.; Trivellin, N.; Unni, V.; Uren, M. J.; Van Hove, M.; Wallis, D. J.; Wang, J.; Xie, J.; Yagi, S.; Yang, S.; Youtsey, C.; Yu, R.; Zanoni, E.; Zeltner, S.; Zhang, Y. The 2018 GaN Power Electronics Roadmap. J. Phys. D: Appl. Phys. 2018, 51 (16), 163001

(3) Izyumskaya, N.; Avrutin, V.; Ding, K.; Özgür, Ü.; Morkoç, H.; Fujioka, H. Emergence of High Quality Sputtered III-Nitride Semiconductors and Devices. Semicond. Sci. Technol. 2019, 34 (9), 093003.

(4) Liu, S.; Yang, S.; Tang, Z.; Jiang, Q.; Liu, C.; Wang, M.; Chen, K. J. Performance Enhancement of Normally-off $\mathrm{Al}_{2} \mathrm{O}_{3} / \mathrm{AlN} / \mathrm{GaN}$ MOSChannel-HEMTs with an ALD-Grown AlN Interfacial Layer. In 2014 IEEE $26^{\text {th }}$ International Symposium on Power Semiconductor Devices \& IC's (ISPSD); IEEE, 2014; pp 362-365 DOI: 10.1109/ ISPSD.2014.6856051.

(5) Koehler, A. D.; Nepal, N.; Anderson, T. J.; Tadjer, M. J.; Hobart, K. D.; Eddy, C. R.; Kub, F. J. Atomic Layer Epitaxy AlN for Enhanced AlGaN/GaN HEMT Passivation. IEEE Electron Device Lett. 2013, 34 (9), 1115-1117.

(6) Chen, K. J.; Huang, S. AlN Passivation by Plasma-Enhanced Atomic Layer Deposition for GaN-Based Power Switches and Power Amplifiers. Semicond. Sci. Technol. 2013, 28 (7), 074015.

(7) Hua, M.; Lu, Y.; Liu, S.; Liu, C.; Fu, K.; Cai, Y.; Zhang, B.; Chen, K. J. Compatibility of AlN/SiNx Passivation With LPCVD-SiNx Gate Dielectric in GaN-Based MIS-HEMT. IEEE Electron Device Lett. 2016, 37 (3), 265-268.

(8) Tzou, A. J.; Chu, K. H.; Lin, I. F.; Østreng, E.; Fang, Y. S.; Wu, X. P.; Wu, B. W.; Shen, C. H.; Shieh, J. M.; Yeh, W. K.; Chang, C. Y.; Kuo, H. C. AlN Surface Passivation of GaN-Based High Electron Mobility Transistors by Plasma-Enhanced Atomic Layer Deposition. Nanoscale Res. Lett. 2017, 12 (1), 315.

(9) Zhu, J. J.; Ma, X. H.; Xie, Y.; Hou, B.; Chen, W. W.; Zhang, J. C.; Hao, Y. Improved Interface and Transport Properties of AlGaN/GaN MIS-HEMTs With PEALD-Grown AIN Gate Dielectric. IEEE Trans. Electron Devices 2015, 62 (2), 512-518.

(10) Rontu, V.; Sippola, P.; Broas, M.; Ross, G.; Sajavaara, T.; Lipsanen, H.; Paulasto-Kröckel, M.; Franssila, S. Atomic Layer Deposition of AlN from $\mathrm{AlCl} 3$ Using $\mathrm{NH} 3$ and $\mathrm{Ar} / \mathrm{NH} 3$ Plasma. J. Vac. Sci. Technol., A 2018, 36 (2), 021508.

(11) Tian, L.; Ponton, S.; Benz, M.; Crisci, A.; Reboud, R.; Giusti, G.; Volpi, F.; Rapenne, L.; Vallée, C.; Pons, M.; et al. Aluminum Nitride Thin Films Deposited by Hydrogen Plasma Enhanced and Thermal Atomic Layer Deposition. Surf. Coat. Technol. 2018, 347, 181-190.

(12) Bosund, M.; Sajavaara, T.; Laitinen, M.; Huhtio, T.; Putkonen, M.; Airaksinen, V. M.; Lipsanen, H. Properties of AlN Grown by Plasma Enhanced Atomic Layer Deposition. Appl. Surf. Sci. 2011, 257 (17), 7827-7830.

(13) Alevli, M.; Ozgit, C.; Donmez, I.; Biyikli, N. The Influence of N2/H2 and Ammonia N Source Materials on Optical and Structural Properties of AlN Films Grown by Plasma Enhanced Atomic Layer Deposition. J. Cryst. Growth 2011, 335 (1), 51-57. 
(14) Van Bui, H.; Wiggers, F. B.; Gupta, A.; Nguyen, M. D.; Aarnink, A. A. I.; de Jong, M. P.; Kovalgin, A. Y. Initial Growth, Refractive Index, and Crystallinity of Thermal and Plasma-Enhanced Atomic Layer Deposition AlN Films. J. Vac. Sci. Technol., A 2015, 33 (1), 01A111.

(15) Perros, A. P.; Hakola, H.; Sajavaara, T.; Huhtio, T.; Lipsanen, $\mathrm{H}$. Influence of Plasma Chemistry on Impurity Incorporation in AlN Prepared by Plasma Enhanced Atomic Layer Deposition. J. Phys. D: Appl. Phys. 2013, 46 (50), 505502.

(16) Alevli, M.; Gungor, N. Influence of N2/H2 and N2 Plasma on Binary III-Nitride Films Prepared by Hollow-Cathode PlasmaAssisted Atomic Layer Deposition. J. Vac. Sci. Technol., A 2018, 36 (1), 01A110.

(17) Broas, M.; Sippola, P.; Sajavaara, T.; Vuorinen, V.; Pyymaki Perros, A.; Lipsanen, H.; Paulasto-Kröckel, M. Structural and Chemical Analysis of Annealed Plasma-Enhanced Atomic Layer Deposition Aluminum Nitride Films. J. Vac. Sci. Technol., A 2016, 34 (4), 041506.

(18) Erwin, S. C.; Lyons, J. L. Atomic Layer Epitaxy of Aluminum Nitride: Unraveling the Connection between Hydrogen Plasma and Carbon Contamination. ACS Appl. Mater. Interfaces 2018, 10 (23), 20142-20149.

(19) Kot, M.; Henkel, K.; Naumann, F.; Gargouri, H.; Lupina, L.; Wilker, V.; Kus, P.; Pozarowska, E.; Garain, S.; Rouissi, Z.; et al. Comparison of Plasma-Enhanced Atomic Layer Deposition AlN Films Prepared with Different Plasma Sources. J. Vac. Sci. Technol., A 2019, 37 (2), 020913.

(20) Kim, H.; Jeon, H. DC Biased Remote Plasma Atomic Layer Deposition and Its Applications. ECS Trans. 2010, 33 (2), 395-401.

(21) Kim, H.; Woo, S.; Lee, J.; Kim, Y.; Lee, H.; Choi, I. J.; Kim, Y. D.; Chung, C. W.; Jeon, H. Effect of DC Bias on the Plasma Properties in Remote Plasma Atomic Layer Deposition and Its Application to HfO2 Thin Films. J. Electrochem. Soc. 2011, 158 (1), $\mathrm{H} 21$.

(22) Profijt, H. B.; van de Sanden, M. C. M.; Kessels, W. M. M. Substrate Biasing during Plasma-Assisted ALD for Crystalline PhaseControl of TiO2 Thin Films. Electrochem. Solid-State Lett. 2011, 15 (2), G1-G3.

(23) Profijt, H. B.; van de Sanden, M. C. M.; Kessels, W. M. M. Substrate-Biasing during Plasma-Assisted Atomic Layer Deposition to Tailor Metal-Oxide Thin Film Growth. J. Vac. Sci. Technol., A 2013, 31 (1), 01A106.

(24) Karwal, S.; Verheijen, M. A.; Williams, B. L.; Faraz, T.; Kessels, W. M. M.; Creatore, M. Low Resistivity HfNx Grown by PlasmaAssisted ALD with External Rf Substrate Biasing. J. Mater. Chem. C 2018, 6 (15), 3917-3926.

(25) Beladiya, V.; Faraz, T.; Kessels, W. M. M.; Tünnermann, A.; Szeghalmi, A. V. Controlling Mechanical, Structural, and Optical Properties of $\mathrm{Al}_{2} \mathrm{O}_{3}$ Thin Films Deposited by Plasma-Enhanced Atomic Layer Deposition with Substrate Biasing. In Advances in Optical Thin Films VI; Lequime, M., Macleod, H. A., Ristau, D., Eds.; SPIE, 2018; p 13 DOI: 10.1117/12.2312516.

(26) Faraz, T.; Knoops, H. C. M.; Verheijen, M. A.; van Helvoirt, C. A. A.; Karwal, S.; Sharma, A.; Beladiya, V.; Szeghalmi, A.; Hausmann, D. M.; Henri, J.; Creatore, M.; Kessels, W. M. M. Tuning Material Properties of Oxides and Nitrides by Substrate Biasing during PlasmaEnhanced Atomic Layer Deposition on Planar and 3D Substrate Topographies. ACS Appl. Mater. Interfaces 2018, 10 (15), 1315813180.

(27) Faraz, T.; Arts, K.; Karwal, S.; Knoops, H. C. M.; Kessels, W. M. M. Energetic Ions during Plasma-Enhanced Atomic Layer Deposition and Their Role in Tailoring Material Properties. Plasma Sources Sci. Technol. 2019, 28 (2), 024002.

(28) Ratzsch, S.; Kley, E. B.; Tünnermann, A.; Szeghalmi, A. Inhibition of Crystal Growth during Plasma Enhanced Atomic Layer Deposition by Applying BIAS. Materials 2015, 8 (11), 7805-7812.

(29) Cao, D.; Cheng, X.; Xie, Y. H.; Zheng, L.; Wang, Z.; Yu, X.; Wang, J.; Shen, D.; Yu, Y. Effects of Rapid Thermal Annealing on the
Properties of AlN Films Deposited by PEALD on AlGaN/GaN Heterostructures. RSC Adv. 2015, 5 (47), 37881-37886.

(30) Zhu, J. J.; Ma, X. H.; Chen, W. W.; Hou, B.; Xie, Y.; Hao, Y. Comparative Study on Interface and Bulk Charges in AlGaN/GaN Metal-Insulator-Semiconductor Heterostructures with Al2O3, AlN, and Al2O3/AlN Laminated Dielectrics. Jpn. J. Appl. Phys. 2016, 55 (5S), 05FH01.

(31) Liu, C.; Liu, S.; Huang, S.; Li, B.; Chen, K. J. AlN/GaN Heterostructure TFTs with Plasma Enhanced Atomic Layer Deposition of Epitaxial AlN Thin Film. Phys. status solidi 2014, 11 (3-4), 953-956.

(32) Zhu, J. J.; Ma, X. H.; Hou, B.; Chen, L. X.; Zhu, Q.; Hao, Y. Comparative Study on Nitridation and Oxidation Plasma Interface Treatment for AlGaN/GaN MIS-HEMTs with AlN Gate Dielectric. Mater. Res. Express 2017, 4 (2), 025902.

(33) Huang, S.; Jiang, Q.; Yang, S.; Zhou, C.; Chen, K. J. Effective Passivation of AlGaN/GaN HEMTs by ALD-Grown AlN Thin Film. IEEE Electron Device Lett. 2012, 33 (4), 516-518.

(34) Hwang, Y. H.; Ahn, S.; Dong, C.; Ren, F.; Gila, B. P.; Hays, D.; Pearton, S. J.; Lo, C. F.; Johnson, J. W. High Breakdown Voltage in AlN/GaN Metal-Insulator-Semiconductor High-Electron-Mobility Transistors. J. Vac. Sci. Technol., B: Nanotechnol. Microelectron.: Mater., Process., Meas., Phenom. 2014, 32 (5), 051204.

(35) Kim, H.; Kim, D. H.; Choi, B. J. Interfacial and Electrical Properties of Al2O3/GaN Metal-Oxide-Semiconductor Junctions with Ultrathin AlN Layer. Appl. Phys. A: Mater. Sci. Process. 2017, 123 (12), 800.

(36) Ozgit, C.; Donmez, I.; Alevli, M.; Biyikli, N. Self-Limiting LowTemperature Growth of Crystalline AlN Thin Films by PlasmaEnhanced Atomic Layer Deposition. Thin Solid Films 2012, 520 (7), $2750-2755$.

(37) Motamedi, P.; Cadien, K. XPS Analysis of AlN Thin Films Deposited by Plasma Enhanced Atomic Layer Deposition. Appl. Surf. Sci. 2014, 315 (1), 104-109.

(38) Rosenberger, L.; Baird, R.; McCullen, E.; Auner, G.; Shreve, G. XPS Analysis of Aluminum Nitride Films Deposited by Plasma Source Molecular Beam Epitaxy. Surf. Interface Anal. 2008, 40 (9), 12541261.

(39) Gredelj, S.; Gerson, A. R.; Kumar, S.; Cavallaro, G. P. Characterization of Aluminium Surfaces with and without Plasma Nitriding by X-Ray Photoelectron Spectroscopy. Appl. Surf. Sci. 2001, 174 (3-4), 240-250.

(40) Ishihara, M.; Yumoto, H.; Tsuchiya, T.; Akashi, K. Effect of Bias Voltage on AlN Thin Films Prepared by Electron Shower Method. Thin Solid Films 1996, 281-282 (1-2), 321-323.

(41) Dalmau, R.; Collazo, R.; Mita, S.; Sitar, Z. X-Ray Photoelectron Spectroscopy Characterization of Aluminum Nitride Surface Oxides: Thermal and Hydrothermal Evolution. J. Electron. Mater. 2007, 36 (4), 414-419.

(42) Fauquier, L.; Pelissier, B.; Jalabert, D.; Pierre, F.; Doloy, D.; Beitia, C.; Baron, T. Depth Profiling Analysis of HfON on SiON Ultrathin Films by Parallel Angle Resolved X-Ray Photoelectron Spectroscopy and Medium Energy Ion Scattering. Surf. Interface Anal. 2016, 48 (7), 436-439.

(43) Cumpson, P. J.; Seah, M. P. Elastic Scattering Corrections in AES and XPS. II. Estimating Attenuation Lengths and Conditions Required for Their Valid Use in Overlayer/Substrate Experiments. Surf. Interface Anal. 1997, 25 (6), 430-446.

(44) Mahjoub, M. A.; Haffner, T.; Labau, S.; Eustache, E.; Aubin, J.; Hartmann, J. M.; Ghibaudo, G.; Pelissier, B.; Bassani, F.; Salem, B. Impact of Wet Treatments on the Electrical Performance of Ge0.9Sn0.1-Based p-MOS Capacitors. ACS Appl. Electron. Mater. 2019, 1 (2), 260-268

(45) Sze, S. M.; Ng, K. K. Physics of Semiconductor Devices, $3^{\text {rd }}$ ed.; Wiley-Interscience, 2006.

(46) Firek, P.; Wáskiewicz, M.; Stonio, B.; Szmidt, J. Properties of AlN Thin Films Deposited by Means of Magnetron Sputtering for ISFET Applications. Mater. Sci.-Pol. 2015, 33 (4), 669-676. 
(47) Adam, T.; Kolodzey, J.; Swann, C. P.; Tsao, M. W.; Rabolt, J. F. The Electrical Properties of MIS Capacitors with ALN Gate Dielectrics. Appl. Surf. Sci. 2001, 175-176, 428-435.

(48) Simeonov, S.; Bakalova, S.; Kafedjiiska, E.; Grigorescu, S.; Sima, F.; Socol, G.; Mihailescu, I. N. Al/AIN/Si MIS Structures with PulsedLaser-Deposited AlN Films as Gate Dielectrics: Electrical Properties. Rom. J. Inf. Sci. Technol. 2007, 10 (3), 251-259.

(49) Ouisse, T.; Schenk, H. P. D.; Karmann, S.; Kaiser, U. Electrical Characterization of the AlN/Si(111) System. Mater. Sci. Forum 1998, 264-268 (2), 1389-1392.

(50) Simoen, E.; Visalli, D.; Van Hove, M.; Leys, M.; Borghs, G. A Deep-Level Analysis of Ni-Au/AlN/( 1111$)$ P+-Si Metal-InsulatorSemiconductor Capacitors. J. Phys. D: Appl. Phys. 2011, 44 (47), 475104.

(51) Wang, C.; Zhao, M.; Li, W.; Simoen, E. Impact of In Situ Annealing on the Deep Levels in Ni-Au/AlN/Si Metal-InsulatorSemiconductor Capacitors. Phys. Status Solidi A 2019, 216 (17), 1900248.

(52) Bi, Z. X.; Zheng, Y. D.; Zhang, R.; Gu, S. L.; Xiu, X. Q.; Zhou, L. L.; Shen, B.; Chen, D. J.; Shi, Y. Dielectric Properties of AlN Film on Si Substrate. J. Mater. Sci.: Mater. Electron. 2004, 15 (5), 317-320.

(53) Xi, D. J.; Zheng, Y. D.; Chen, P.; Chu, R. M.; Gu, S. L.; Shen, B.; Zhang, R. Study on the AlN/Si Interface Properties. Opt. Mater. (Amsterdam, Neth.) 2003, 23 (1-2), 143-146.

(54) O’Leary, S. K.; Foutz, B. E.; Shur, M. S.; Eastman, L. F. SteadyState and Transient Electron Transport Within the III-V Nitride Semiconductors, GaN, AlN, and InN: A Review. J. Mater. Sci.: Mater. Electron. 2006, 17 (2), 87-126. 